\title{
diffusion-înirdarneritals
}

The Open-Access Journal for the Basic Principles of Diffusion Theory, Experiment and Application

\section{Long-term observation of adsorbed heavy metal ions in sediment samples by MRI}

\author{
Nikolaus Nestle ${ }^{1,2}$, Martin Ebert ${ }^{3}$, Arthur Wunderlich ${ }^{4}$, Thomas Baumann ${ }^{5}$ \\ ${ }^{1}$ TU Darmstadt, Institute of Condensed Matter Physics, Darmstadt, Germany \\ ${ }^{2}$ Present adress: BASF AG Ludwigshafen, Germany \\ ${ }^{3}$ TU Darmstadt, Institute of Environmental Mineralogy, Darmstadt, Germany \\ ${ }^{4}$ University of Ulm, Department of Diagnostic Radiology, \\ ${ }^{5}$ TU Munich, Institute of Hydrochemistry
}

Corresponding author: Nikolaus Nestle, TUD-IFP, Hochschulstraße 6, D-64289 Darmstadt, Germany, E-Mail: nikolaus.nestle@physik.tu-darmstadt.de

(received 30 May 2007, accepted 7 June 2007)

\begin{abstract}
Recently, we have reported studies of transport and sorption of heavy metal ions in watersaturated quartz sand columns under relatively fast water flow. In these experiments, clear indications for a fast and strong adsorption of the ions to the sediment could be found. Here we report the findings in a series of other experiments performed under static conditions. In this case, much higher concentrations of ions are adsorbed to the sand and remain immobile over time scales of more than a year. Changes in the MRI contrast observed for the sediment areas with the adsorbed ions indicate rearrangements in the distribution of the ions during the first days after administration to the sediment. EDX-studies of the ion distribution after several days indicate a spatially inhomogeneous distribution of adsorbed ions on the surface of the quartz sand. If the adsorbed ions are subjected to flow, a part of adsorbed ions moves away with the water flow. Also all ions are rapidly accessible to acid leaching.
\end{abstract}

Copyrights Nikolaus Nestle

\section{Keywords}

MRI, contaminant transport, hydrogeology, diffusion

\section{Introduction}

In our recent MRI studies on sorption of heavy metal ions in quartz sand [1,2], we have locally injected solutions of paramagnetic heavy metal ions at concentrations in the $100 \mathrm{mg} / \mathrm{l}$ 
range into flow columns packed with water-saturated quartz sand. When the injected bolus of heavy metal ions propagated along the column with the water flow, the formation of a welldefined sorption trace could be observed. After all injected ions were immobilized in such a sorption trace, its shape remained stable over several hours under water flow. In multiplepassage experiments, indications were found that an equilibrium concentration of adsorbed ions was reached already during the first passage of heavy metal ions under these conditions [2]. The evaluation of the sorption traces in those flow cell experiments was based on the volume of the traces and the elemental amount of heavy metal ions used in the experiments. Discrimination between the virgin sediment and sediment with adsorbed heavy metal ions was possible on the basis of the sufficiently strong changes in the NMR relaxation times of the pore water due to the presence of the adsorbed paramagnetic ions (see section 1 of the supporting information for a short description of NMR relaxation time weighting in MRI).

A way to extract more detailed information from MRI data than in such a segmentation approach is the quantitative analysis of the signal distribution and the underlying relaxation times. If the relationship between the concentration of adsorbed ions and the pore water relaxation time would be known, this could be used for producing actual concentration maps of the ions. In experiments aiming at such a quantification we have made some observations that on the one hand severely complicate the establishment of a simple relationship between contrast and ion concentration but on the other hand may provide interesting insights into the interaction of the ions with the sediment. These effects shall be documented and discussed in this article.

In solution, the relaxation rates (i.e. reciprocal NMR relaxation times) of the water protons increase linearly with the concentration of the dissolved paramagnetic ions:

$$
\frac{1}{T_{i}}=\frac{1}{T_{i, o}}+R_{i} c
$$

with $T_{i}$ denoting the relaxation time of the solution, $T_{i, o}$ the relaxation time of the pure water, $R_{i}$ the relaxivity and $c$ the concentration of the dissolved ions. The index $i$ is either 1 for the longitudinal relaxation time or 2 for the transverse relaxation time. The relaxivities of paramagnetic ions in solution have been intensively studied [3]. The increase in the water proton relaxation rates brought about by the presence of paramagnetic complexes in solution is also used for contrast agents in medical MRI [3]. In the context of such biomedical applications, the NMR relaxation in solutions of paramagnetic complexes or free paramagnetic ions has been intensively studied.

The contrast in a standard gradient echo MRI experiment depends on both the longitudinal and the transverse relaxation time:

$$
S(x, y)=S_{o}(x, y) \sin (\vartheta) \frac{\exp \left(-\frac{t_{e}}{T_{2}(x, y)}\right)\left(1-\exp \left(-\frac{t_{R}}{T_{1}(x, y)}\right)\right)}{1-\cos (\vartheta) \exp \left(-\frac{t_{R}}{T_{1}(x, y)}\right)}
$$

with $S_{0}(\mathrm{x}, \mathrm{y})$ denoting the spin density (i.e. the amount of NMR-excitable material), $T_{l}(x, y)$ and $T_{2}(x, y)$ denoting the longitudinal resp. the transverse relaxation time in the voxel and $\vartheta$ 
the excitation angle and $t_{e}$ the echo and $t_{R}$ the repetition time employed in the MRI sequence. (For a detailed description of the basic principles of MRI see e.g. [4,5].)

Although relaxation at paramagnetic centres on pore surfaces in sediments has been known for a long time as a relevant phenomenon in NMR studies of porous media [6,7], only limited information is available on the relaxation behaviour of water in the presence of paramagnetic centers (typically $\mathrm{Fe}$ - and $\mathrm{Mn}$-ions) adsorbed to pore walls or inorganic particles $[8,9,10]$. From this work, it is obvious that bulk relaxivities for aqueous solutions of paramagnetic ions cannot be used for a quantitative evaluation of the concentration of adsorbed ions as both the relaxation time of water molecules adsorbed to the respective ions and their residence time there can be considerably different from the respective values in solution. No experimental data for $\mathrm{Gd}^{3+}$ or $\mathrm{Cr}^{3+}$ ions adsorbed to quartz or similar sediment surfaces are known to us from literature. Due to the complex interplay between several correlation times and the different structure of the coordination sphere that can be expected for the adsorbed ions compared to free ions, making quantitative predictions on the basis of models from literature $[3,9]$ does not seem possible.

We therefore tried to conduct a calibration experiment in which sand samples equilibrated with heavy metal solutions of different concentrations were studied. As we had no access to a relaxometry setup operating at $60 \mathrm{MHz}$ at the time of these experiments, we restricted ourselves to evaluating the concentration dependence of the MRI signal intensities in for various relaxation-time weightings as obtained from imaging a collection of bottles filled with the sand samples (see figure 1).

This approach is also used in clinical MRI for evaluating relaxation times e.g. of contrast agent samples [11]. Although some increase of the signal intensity with the concentration of the adsorbed ions could be observed, this increase neither was monotonic nor linear with the concentration of the ions as should be expected on the basis of the information from the literature.

As the concentration of the ions in the sample with the highest $\mathrm{Gd}^{3+}$ concentrations was considerably higher than the sorption capacity of $26 \mathrm{mg} / \mathrm{kg}$ dry sand determined in the flow experiments for this kind of sand, the observed signal intensity for this sample was also surprisingly low: Based on the assumption that the $\mathrm{Gd}^{3+}$ ions exceeding the sorption capacity are present in the pore solution as free $\mathrm{Gd}^{3+}$, the resulting signal intensity should be at least $50 \%$ higher than the observed value. While these findings were not really helpful in providing a basis for a more quantitative evaluation of the relaxation time contrast in the adsorption experiments, they indicate that further effects need to be taken into account when trying to quantify the relationship between relaxation times and ion concentration in the quartz sand samples. In order to study these effects, a series of imaging experiments on static watersaturated sand samples was conducted in which the NMR behaviour of $\mathrm{Gd}^{3+}$ ions injected into sand sediments was investigated under static conditions and over a long time. 

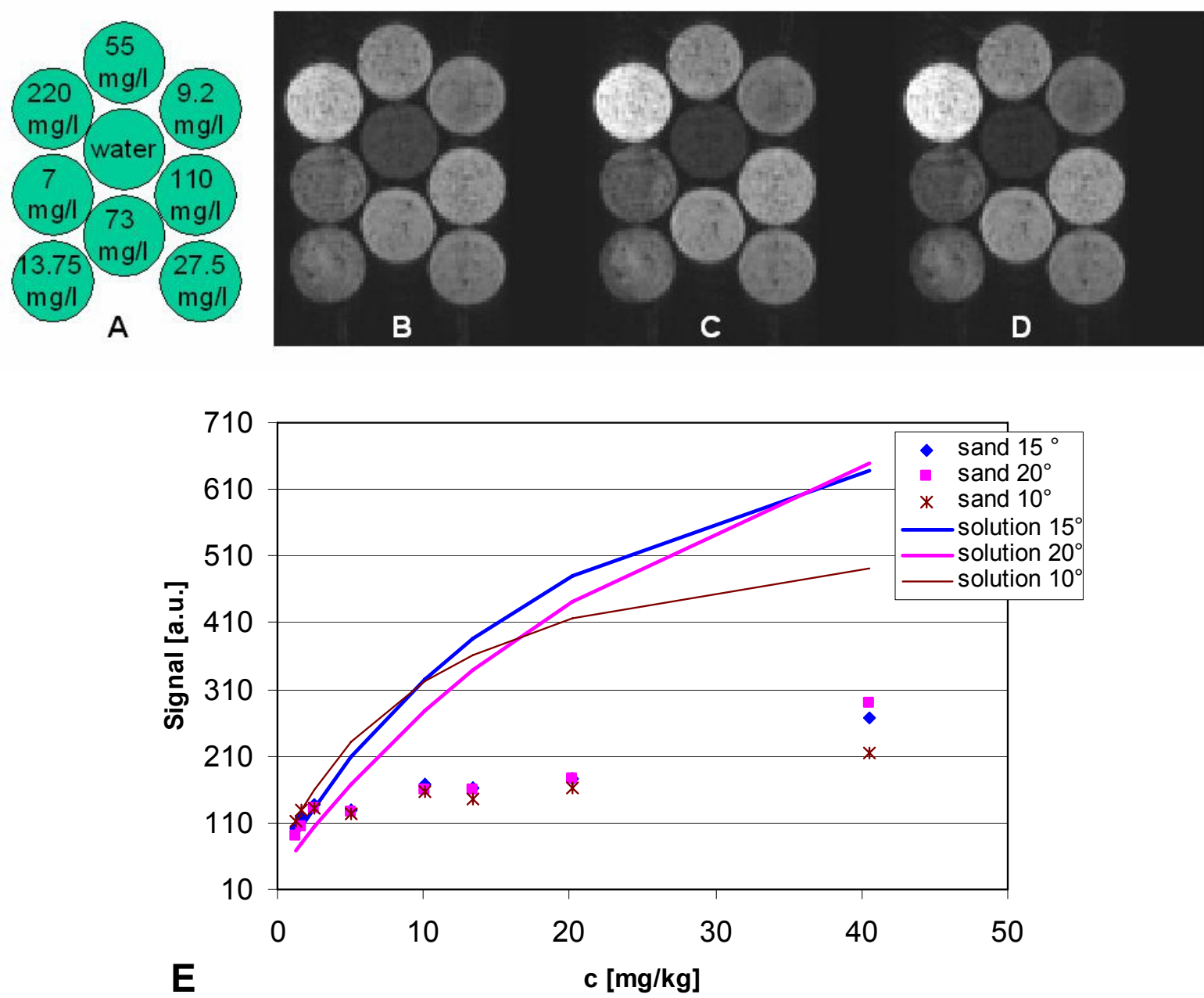

Figure 1 Tentative determination of the relationship between the Gd content and signal intensities in FLASH experiments with different excitation angles. (A) Arrangement of the bottles with different Gd concentrations. (B) FLASH image with $10^{\circ}$ excitation angle, (C) FLASH image with $15^{\circ}$ excitation angle, (D) FLASH image with $20^{\circ}$ excitation angle. Further parameters in the FLASH images: TR=4.4 ms, TE=1.8 ms, 16 scans, data matrix: $128 \times 128$ data points, slice thickness: $2.5 \mathrm{~mm}$, in-plane-resolution: $(1.95 \mathrm{~mm})^{2}$. (E) Signal intensities determined from the FLASH images and expected signal intensities computed on the basis of bulk water relaxivities of $\mathrm{Gd}^{3+}$ using eqn. (2). While a clear increase of the signal intensities is observed for the lowest concentrations, the overall increase in the signal intensity is much smaller than expected with the bulk relaxivities, and the dependence on the excitation angle only matches the expectations for the highest concentration.

\section{Materials and Methods}

Quartz sand samples with low iron content were obtained from E+M, Hof, Germany (0.3-0.8 $\mathrm{mm}$ grain size) and from AKW, Hirschau, Germany (0.1-0.5 mm grain size). In order to minimize problems with internal magnetic field gradients, the sands were subjected to magnetic filtration before the experiments [1].

MRI studies were performed on water-saturated sand samples which were housed in plastic bottles and containers (typical sediment volumes one to several litres) made from polypropylene (PP). As for the experiments under flow conditions, the sand samples were prepared by pouring dry sand into the partially water-filled containers [2]. The water used in the experiments was demineralised water with a conductivity of $0.6 \mu \mathrm{S} / \mathrm{cm}$ and a $\mathrm{pH}$ of about 
5.8. In order to be able to compare intensities form MRI data sets obtained in different imaging sessions, small plastic vials with reference fluids were put into the sand packings in most cases.

MRI was performed in the head coil of a standard Siemens Magnetom Vision clinical MRI scanner (Siemens Medical, Erlangen, DE) operating at $63 \mathrm{MHz}$ proton resonance frequency. The head RF coil was used for imaging as it provides a high sensitivity and a field of view which matches the column dimensions. Three different types of imaging sequences were used in the experiments:

- a moderately $\mathrm{T}_{1^{-}}$and $\mathrm{T}_{2}$-weighted multislice spin echo (SE) sequence with a repetition time of $1 \mathrm{~s}$ and an echo time of $17 \mathrm{~ms}$,

- a FLASH (Fast Low Angle SHot) sequence working with TE=1.8 ms, TR=4.4 ms, which was used with various excitation angles ranging from $5^{\circ}$ to $30^{\circ}$. The contrast in this sequence is mainly due to moderate to strong $\mathrm{T}_{1}$ weighting and

- a strongly $\mathrm{T}_{2}$-weighted turbo spin echo (TSE) sequence with $\mathrm{TE}=96 \mathrm{~ms}$, and $\mathrm{TR}=3300$ ms.

A short introduction into MRI and the use of relaxation time contrasts is given in section 1 of the supporting information.

Elemental $\mathrm{Gd}^{3+}$ contents in solutions and pore water samples were determined using ICP-MS (on a Perkin Elmer ELAN 6100).

EDX was performed at a Philips XL30 LAB6 equipped with an EDAX Genesis detector. All imaging and the EDX studies were done in the low vacuum ESEM mode. The use of this ESEM mode allows studying the sand grains without any possibly invasive treatment such as drying or sputtering. In contrast to the MRI samples, the ESEM samples were produced by directly wetting dry quartz sand with a $200 \mathrm{mg} / 1$ solution of $\mathrm{Gd}\left(\mathrm{NO}_{3}\right)_{3}$. In order to remove solution phase Gd, samples with a short exposition time to the solution were rinsed by passage of the 4-fold pore volume in demineralised water before taking a sand sample for the EDX experiment. In all cases, the sand samples were put onto SEM stubs. The acceleration voltage in the electron gun was $20 \mathrm{kV}$. An $\mathrm{LaB}_{6}$ cathode was used.

\section{Results and discussion}

\section{$\underline{3.1 \text { Long-term MRI studies of injected } \mathrm{Gd}^{3+}} \underline{\text { solution }}$}

In order to gain further insights into the relationship between the concentration of heavy metal ions and the relaxation time contrast, a first long-term experiment was run in which two bolusses of $\mathrm{Gd}^{3+}$ solutions with different concentrations were injected into a bottle packed with water-saturated quartz sand and the subsequent changes in the distribution and MR behaviour of the injected ions were observed. As the injected concentration in one of the bolusses was higher than the maximal sorption capacity of the sand known from the flow-cell experiments, we expected a density- and diffusion-driven migration [12,13] of the additional $\mathrm{Gd}^{3+}$ ions into the sand around the injection site and a corresponding growth of the heavymetal-doped sand region until the sorption capacity of the volume matches the amount of injected $\mathrm{Gd}^{3+}$ ions. Such a behaviour could indeed be observed for $\mathrm{Mn}^{2+}$ ions injected into static sand beds (see figure 2 in the supporting information). $\mathrm{Mn}^{2+}$ is known to exhibit only minor sorption effects in silica-based media [14]. 

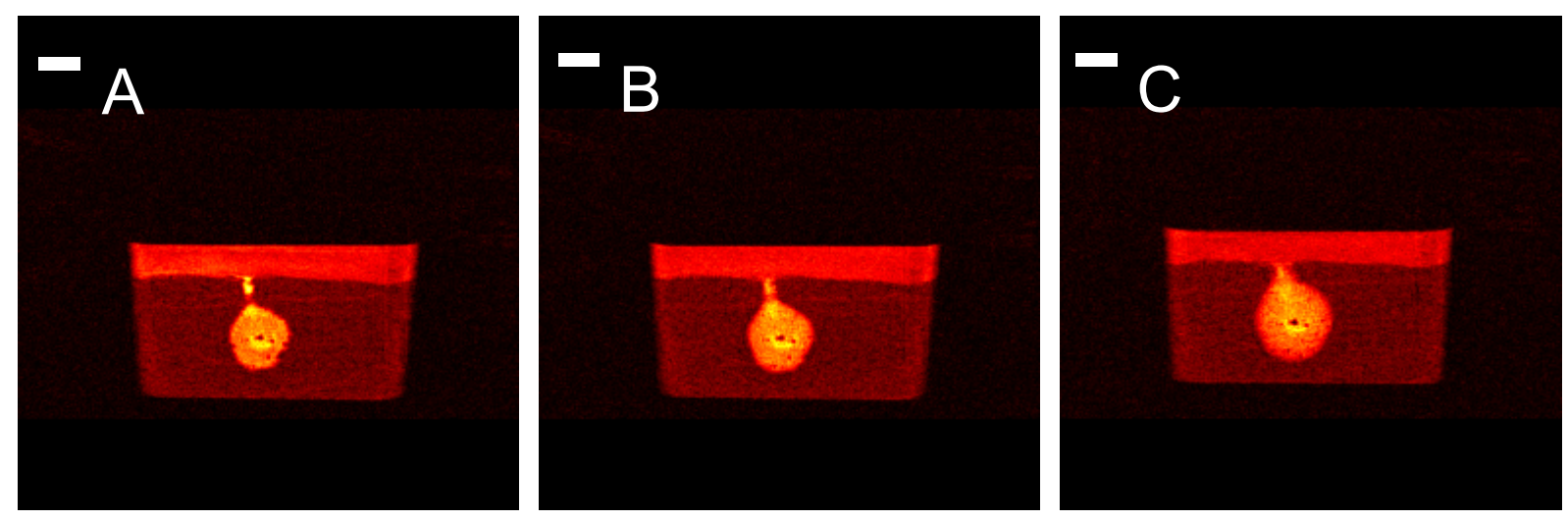

Figure 2 Diffusive spreading of $5 \mathrm{ml} 1.25 \mathrm{mM} \mathrm{Mn}\left(\mathrm{NO}_{3}\right)_{2}$ solution injected into a water-saturated packing of 0.1 $0.5 \mathrm{~mm}$ quartz sand. (A) immediately after injection, (B) $3 \mathrm{~h} 30 \mathrm{~min}$ after injection, (C) $20 \mathrm{~h}$ after injection. FLASH MRI scans with the following parameters: $\mathrm{TR}=4.4 \mathrm{~ms}, \mathrm{TE}=1.8 \mathrm{~ms}$, excitation angle $15^{\circ}$, field of view: $240 \mathrm{~mm} \times 150 \mathrm{~mm}$, slice thickness: $2.5 \mathrm{~mm}$ and in-plane resolution: $(0.94 \mathrm{~mm})^{2}$, the bright bar corresponds to $2 \mathrm{~cm}$. On the basis of the diffusive spreading of the ions, the diffusion coefficient of the $\mathrm{Mn}^{2+}$ ions inside the sand can be estimated as $1.4 \cdot 10^{-10} \mathrm{~m}^{2} / \mathrm{s}$ which seems a reasonable order of magnitude.

However, as can be seen from figure 3, this did not happen for the $\mathrm{Gd}^{3+}$ ions. Instead, we see that the size of the region with positive relaxation time contrast (i.e. containing $\mathrm{Gd}^{3+}$ ions) does not grow with time (note that the images have been taken in different sessions so that the position of the image slices are possibly not perfectly matched due to inaccurate reproduction of the original sample position in the magnet). However, we do see a strong systematic change in the relaxation-time contrast between the region with the injected $\mathrm{Gd}^{3+}$ ions and the surrounding material: The initially much higher signal intensity of the $\mathrm{Gd}^{3+}$-containing region fades out systematically from the outside to the center over the first day after injection.

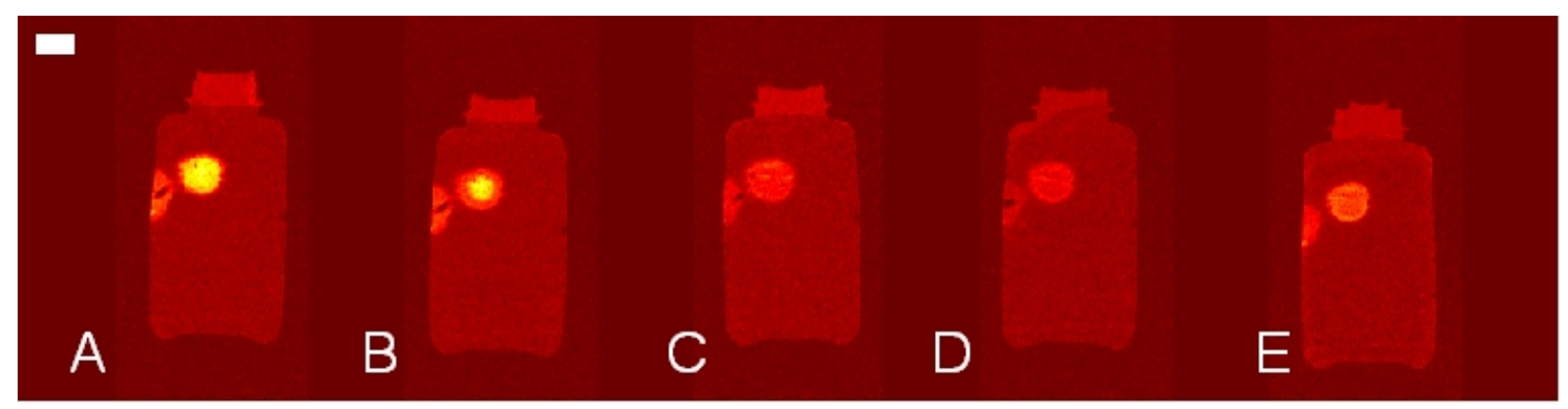

Figure 3: $\mathrm{Gd}^{3+}$ ions injected into a bottle with water-saturated quartz sand (grain size 0.1-0.5 mm). A immediately after injections, B: $2 \mathrm{~h} 30$ min after injections, C: $18 \mathrm{~h}$ after injections, D after 12 days, E: after one year. The $\mathrm{Gd}^{3+}$ ions in both the injection site at the left edge of the bottle $\left(5 \mathrm{ml}\right.$ solution with $\mathrm{Gd}^{3+}$ ions at 33 $\mathrm{mg} / \mathrm{l})$ and the more central one $\left(5 \mathrm{ml}\right.$ with $\mathrm{Gd}^{3+}$ ion at $\left.222 \mathrm{mg} / \mathrm{l}\right)$ remain stationary over the whole time of observation. Note however the characteristic contrast changes in the central injection site during the first hours after injection. (MRI protocol: FLASH with $\mathrm{TR}=4.4 \mathrm{~ms}, \mathrm{Te}=1.8 \mathrm{~ms}$, excitation angle $15^{\circ}$, data matrix: $256 \mathrm{X} 128$ points, 32 slices of $3.12 \mathrm{~mm}$ thickness, in-plane resolution $(0.98 \mathrm{~mm})^{2}$ bright bar: $\left.2.5 \mathrm{~cm}\right)$. Note that all images were acquired in separate MRI scanning sessions so that the slice positions do not mach exactly.

As no indication for any dislocations of $\mathrm{Gd}^{3+}$ ions outside the original injection area was found, the only explanation for this behaviour is a rearrangement of the ions inside the pore system of the injection region. This behaviour is not unique to $\mathrm{Gd}^{3+}$ ions but was also observed in experiments performed with solutions $\mathrm{Cu}^{2+}$ and $\mathrm{Cr}^{3+}$ at the same normality injected into water-saturated sand (see figure 4). For both ions, we observed the formation of a sorption trace with a lower concentration of adsorbed ions in flow cell experiments [1,2]. 


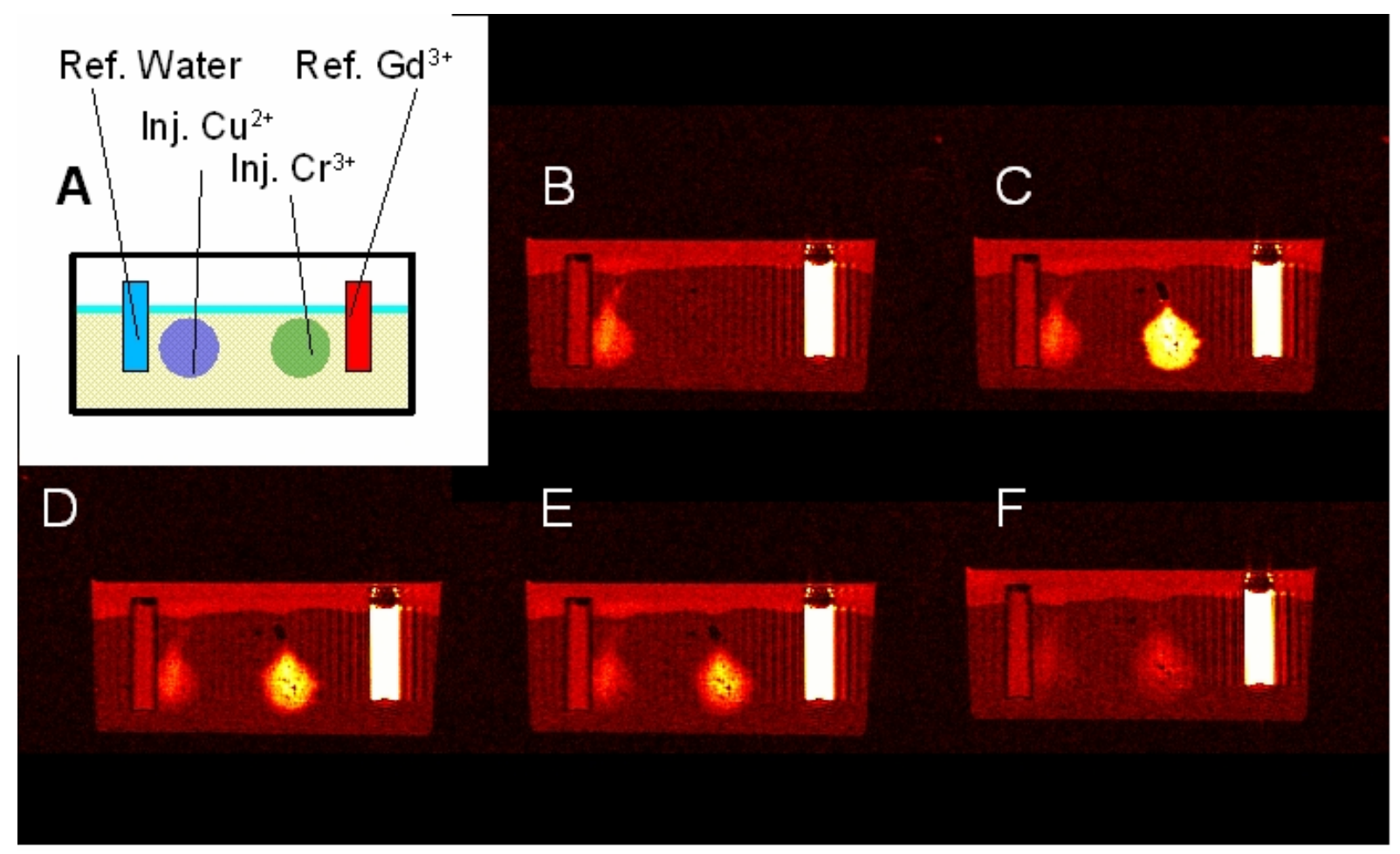

Figure 4 MRI contrast behaviour of $1.88 \mathrm{mM} \mathrm{Cu}\left(\mathrm{NO}_{3}\right)_{2}$ and $1.25 \mathrm{mM} \mathrm{Cr}\left(\mathrm{NO}_{3}\right)_{3}$ solution injected into watersaturated quartz sand with a grain size of 0.1-0-5 mm. A: schematic representation of the injection sites, B: after injection of the $\mathrm{Cu}\left(\mathrm{NO}_{3}\right)_{2}$ solution, $\mathrm{C}$ : after injection of the $\mathrm{Cr}\left(\mathrm{NO}_{3}\right)_{3}$ solution, $\mathrm{D}: 2 \mathrm{~h}$ after the injections, E: $5 \mathrm{~h}$ after the injections, F: $20 \mathrm{~h}$ after the injections. The concentrations of the solutions have been chosen to match the normality of the $220 \mathrm{mg} / \mathrm{l} \mathrm{Gd}^{3+}$ solution used in the first experiments. As the molar relaxivity of the $\mathrm{Cu}^{2+}$ solution is much lower than for $\mathrm{Gd}^{3+}$ and $\mathrm{Cr}^{3+}$, the contrast in this region mainly seems to fade away without a clear structure while in the $\mathrm{Cr}^{3+}$ injection region, the same outside-in contrast change can be observed as for the $\mathrm{Gd}^{3+}$, too. For both ions, no indication for diffuse spreading outside the original injection site could be found.

$\mathrm{Gd}^{3+}$ ions were also studied in a coarser sand with a grain size of $0.3 . .0 .8 \mathrm{~mm}$. In this case, the static sorption capacity of the sand was not sufficient to immobilize all ions in the original injection area (see figure 5). However, the propagation of the ions out of the injection zone came to a halt after the ions had filled a volume corresponding to the static sorption capacity of this sand. From volume rendering, we can estimate this capacity as $28 \mathrm{mg} / \mathrm{kg}$ dry sand (assuming a porosity of 0.4 which was determined from the volume of the originally injected solution). The sorption capacity observed under flow conditions (comparable to those in $[1,2]$ ) for the same type of sand was determined as $10.6 \mathrm{mg} / \mathrm{kg}$ dry sand. 


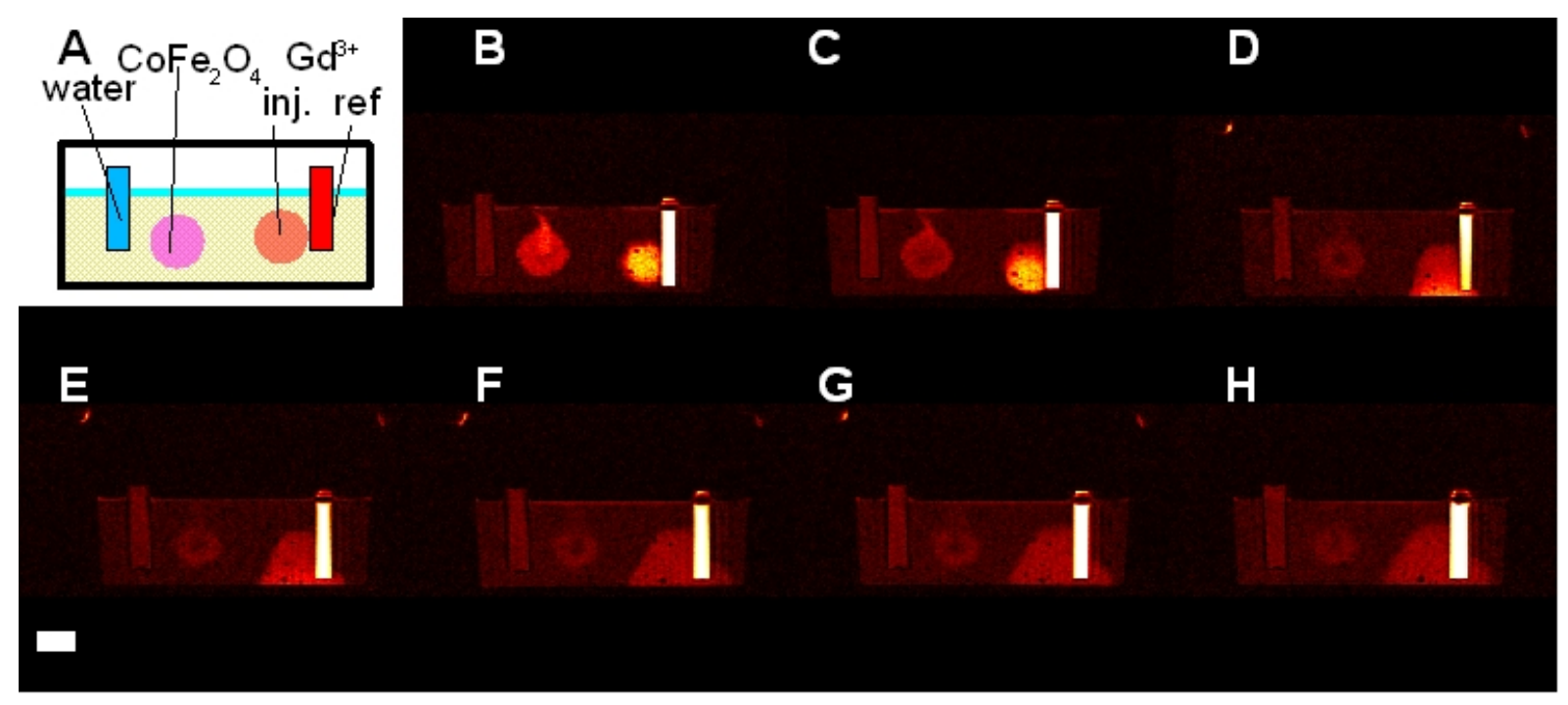

Figure 5 Contrast changes in a static sand cell packed with water saturated quartz sand 0.3-0.8mm grain size. The experimental setup is sketched in A: In the water-saturated sand bed, a reference vial with water (left) and one with $222 \mathrm{mg} / \mathrm{l} \mathrm{Gd}^{3+}$ solution (right) are positioned. Next to the Gd-reference vial, $5 \mathrm{ml}$ of the $222 \mathrm{mg} / 1$ solution of $\mathrm{Gd}^{3+}$ have been injected. In the left half of the column, an additional injection with a $\mathrm{CoFe}_{2} \mathrm{O}_{4}$-based colloid was performed which shall not be further discussed in this paper. The MRI scans were taken at different times B: immediately after injection, C: $2 \mathrm{~h} 30 \mathrm{~min}$ after injection, D $18 \mathrm{~h}$ after injection, E: 2 days after injection, F: 19 days after injection, G: 26 days after injection and H 49 days after injection. . (MRI protocol: FLASH with $\mathrm{TR}=4.4 \mathrm{~ms}$, $\mathrm{Te}=1.8 \mathrm{~ms}$, excitation angle $15^{\circ}$, data matrix: $256 \mathrm{X} 128$ points, 32 slices of $3.12 \mathrm{~mm}$ thickness, in-plane resolution $(0.98 \mathrm{~mm})^{2}$ bright bar: $\left.2.5 \mathrm{~cm}\right)$. Note that all images were acquired in separate MRI scanning sessions so that the slice positions do not mach exactly.

\section{$\underline{3.2 \text { Remobilization of adsorbed Gd under water flow }}$}

The sample shown in figure 5 was subjected to water flow after 7 weeks under static conditions. This was achieved by inserting two additional tubes into the sand packing and starting a circulation of the water by means of a peristaltic pump (see sketch in figure 6).

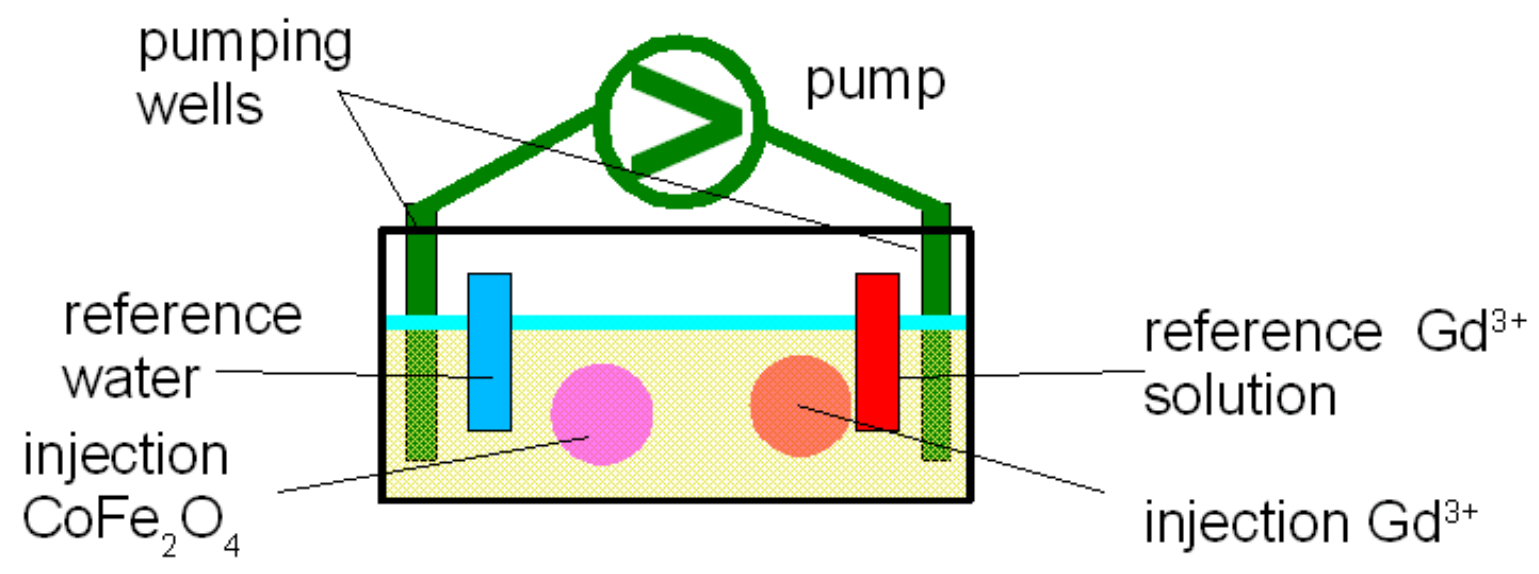

Figure 6 Sketch of the flow setup which was used to study flow-induced mobilization of $\mathrm{Gd}^{3+}$ ions in the sample presented already in figure 2 in the article. The two tubes inserted into the sand bed were made of PP and had an inner diameter of $8 \mathrm{~mm}$. 
The flow rate was $36 \mathrm{ml} / \mathrm{min}$. Figure 7 shows the development in the sample after the installation of the flow injection tubes and after passage of 10 resp. 100 pore volumes through the sample: Due to the flow, a considerable displacement of $\mathrm{Gd}^{3+}$ ions out of the original area of immobilization took place. Together with the observations from the flow column experiments, this suggests the existence of two different types of adsorption sites for $\mathrm{Gd}^{3+}$ ions in the sand: In addition to the strong binding sites responsible for the formation of the sorption traces, other, much weaker binding sites exist which coexist with a notable equilibrium concentration in the solution phase. Volume rendering of the trace before starting the flow and at the two stages shown in figure 7 leads to $58 \mathrm{ml}, 85 \mathrm{ml}$ and $134 \mathrm{ml}$, respectively. From the trace volume increase observed during passage of the 10 first pore volumes, we can estimate a retardation factor of about 350 for the $\mathrm{Gd}^{3+}$ ions with respect to the water flow. Assuming a linear sorption isotherm and only one type of binding sites, this in turn would suggest a distribution coefficient of 350 between bound and adsorbed $\mathrm{Gd}^{3+}$. It should be noted that this is a very rough estimate as we have evidence for the existence of at least two different adsorption binding sites (one responsible for the (stable) adsorption observed in the flow experiments and another much less stable for the additional adsorption under static conditions). The trace volume observed after the passage of 100 pore volumes nicely corresponds to the volume needed to adsorb the amount of Gd present in the system at the concentration measured in the flow experiment. Furthermore, no further change in the $\mathrm{Gd}^{3+}$ distribution could be observed upon passage of 50 pore volumes after reversal of the flow direction.
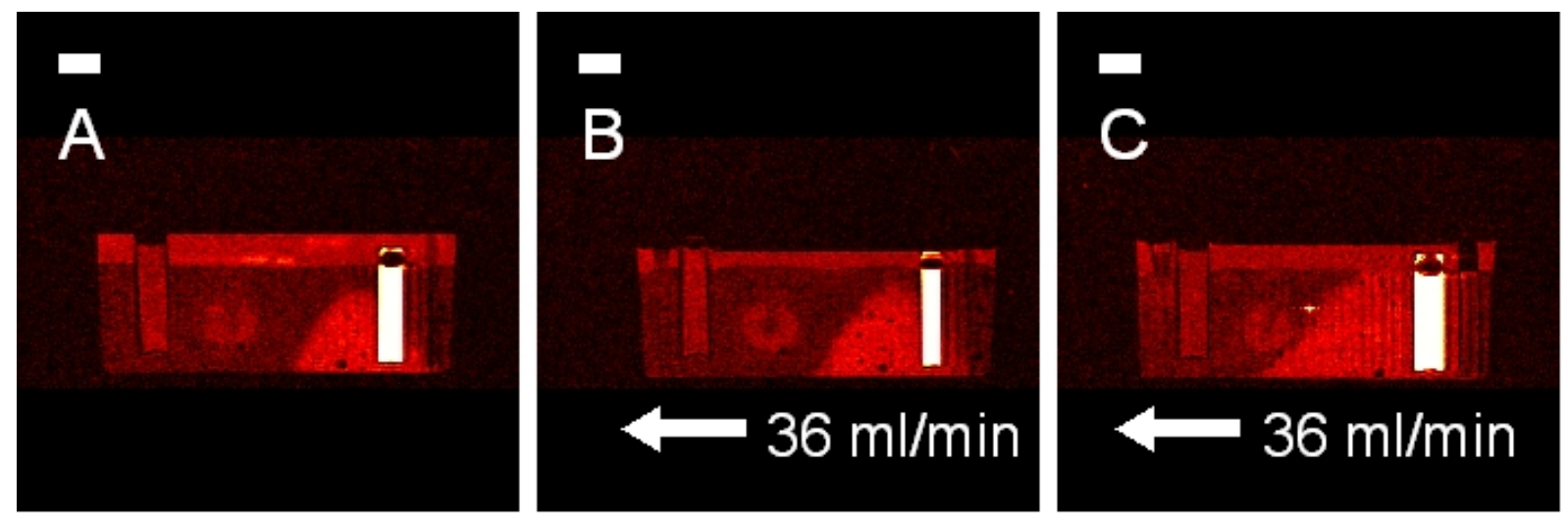

Figure 7 Exposure of the cell used in the experiments presented in figure 2 to flow. (A) before start of flow (B) after passage of 10 pore volumes through the sediment in the direction indicated by the white arrow (C) after passage of 100 pore volumes. Note the slow partial propagation of the $\mathrm{Gd}^{3+}$ ions along the flow direction. . (MRI protocol: FLASH with $\mathrm{TR}=4.4 \mathrm{~ms}, \mathrm{Te}=1.8 \mathrm{~ms}$, excitation angle $15^{\circ}$, data matrix: $256 \mathrm{X} 128$ points, 32 slices of $3.12 \mathrm{~mm}$ thickness, in-plane resolution $(0.98 \mathrm{~mm})^{2}$ bright bar: $\left.2 \mathrm{~cm}\right)$. Note that all images were acquired in separate MRI scanning sessions so that the slice positions do not mach exactly.

\section{$\underline{3.3 \text { ESEM and EDX study of the Gd }}{ }^{3+}$ distribution}

The fast remobilization of $\mathrm{Gd}^{3+}$ ions under flow or upon chemical changes indicates that the adsorbed Gd must be still situated close to the surface of the sand grains. EDX provides an experimental option for elemental analysis and element distribution mapping at high spatial resolution and with a chemical sensitivity down to less than $1 \%$ of the atoms on the surface. ESEM allows the use of this technique on samples without any special pre-treatment that might change the distribution of elements on the surface.

Two sand samples were studied: one was exposed to a $200 \mathrm{mg} / 1$ solution of $\mathrm{Gd}^{3+}$ ions for 10 minutes, and another one for about a week. In the sample which was exposed for 10 minutes, 
no $\mathrm{Gd}^{3+}$ adsorbed to surface structures could be detected. All Gd which was observed on these samples was found in loose, fluffy crystallite structures which were probably formed during the drying of not fully removed Gd-solution in the ESEM (see figure 8).

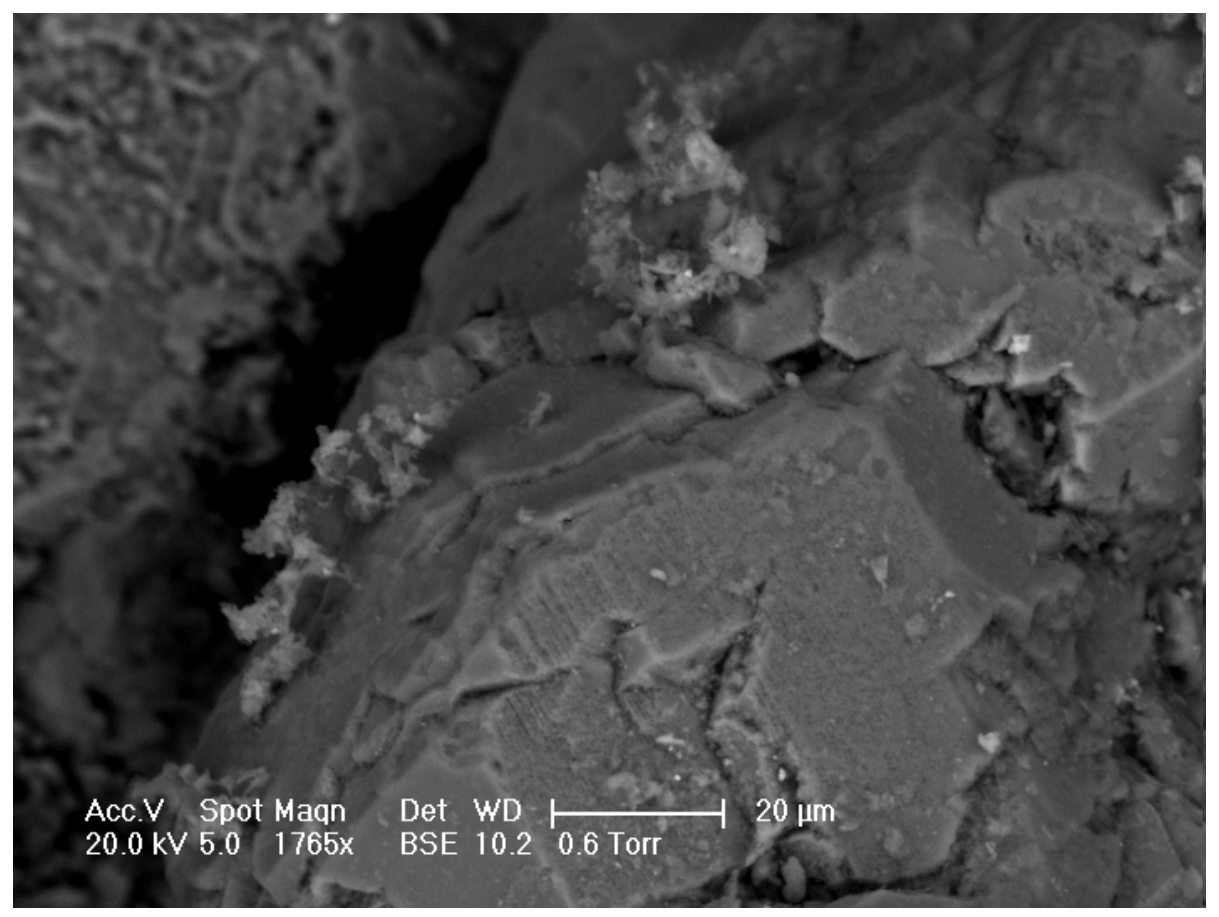

Figure 8 BSE image of loose Gd-containing crystallites laying of the surface of sand grains dryed after 10 min exposure to $\mathrm{Gd}\left(\mathrm{NO}_{3}\right)_{3}$ solution and subsequent rinsing with about 4 pore volumes of water. The crystallites are very unevenly distributed and most probably formed by fast crystallization of residual dissolved Gd during drying in the ESEM (run in environmental mode, not in wet mode).

In the sample which was exposed to Gd solution for a week, no such structures could be observed. Instead, Gd adsorbed to various features of the surface structure could be found:

In a first survey, the microscopic morphology of the sand grains was studied both by conventional SEM and in the backscattered electron (BSE) mode. Examples for the surprisingly rich surface structure of the grains are given in figures 9 to 11 . 


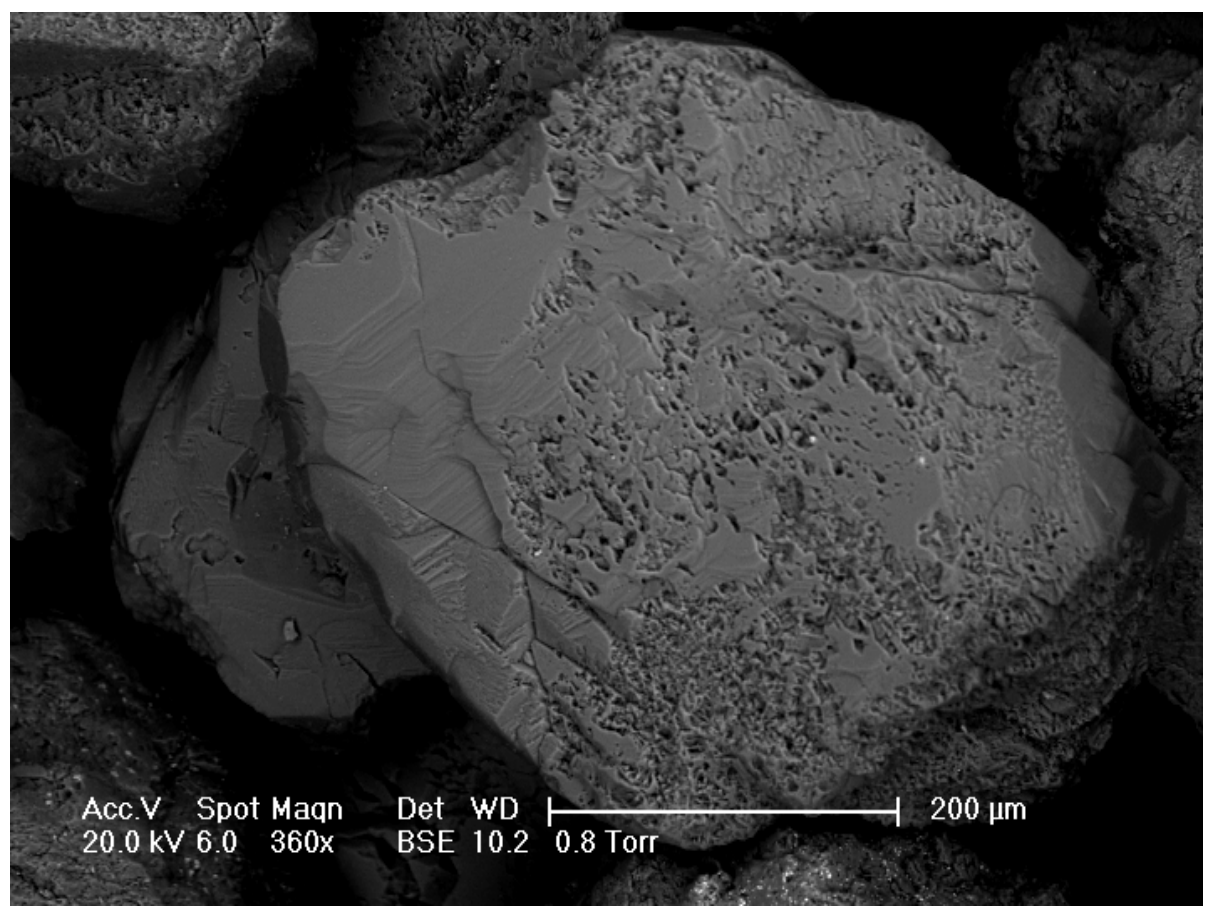

Figure 9 BSE scan of a typical grain of the 0.1-0.5 mm grain size sand: smooth crystalline fracture surfaces (such as on the left half of the grain) and highly corrugated areas can be found on most sand grains. The bright spots indicate the presence of some compounds with heavier elements on the surface. EDX studies of the bright spots indicated the presence of Ti and Ba.

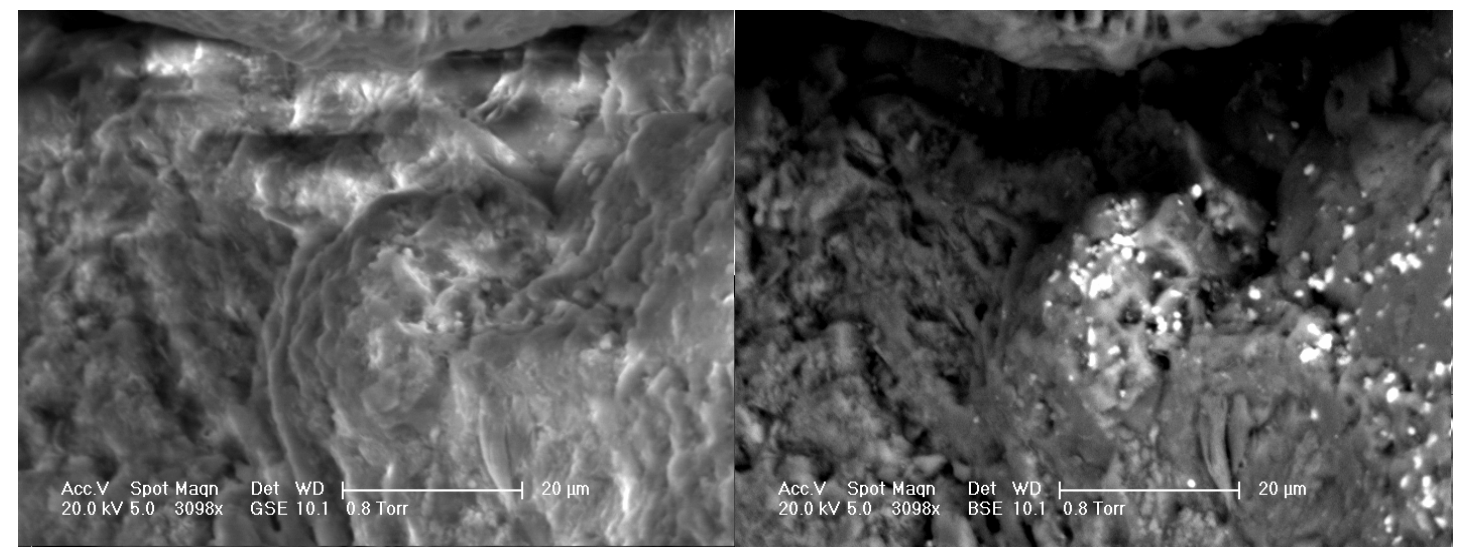

Figure $10 \mathrm{GSE}$ (left) and BSE (right) scan of two adjacent sand grains. Note again the appearance of clearly defined bright spots containing heavier elements in the BSE image. 


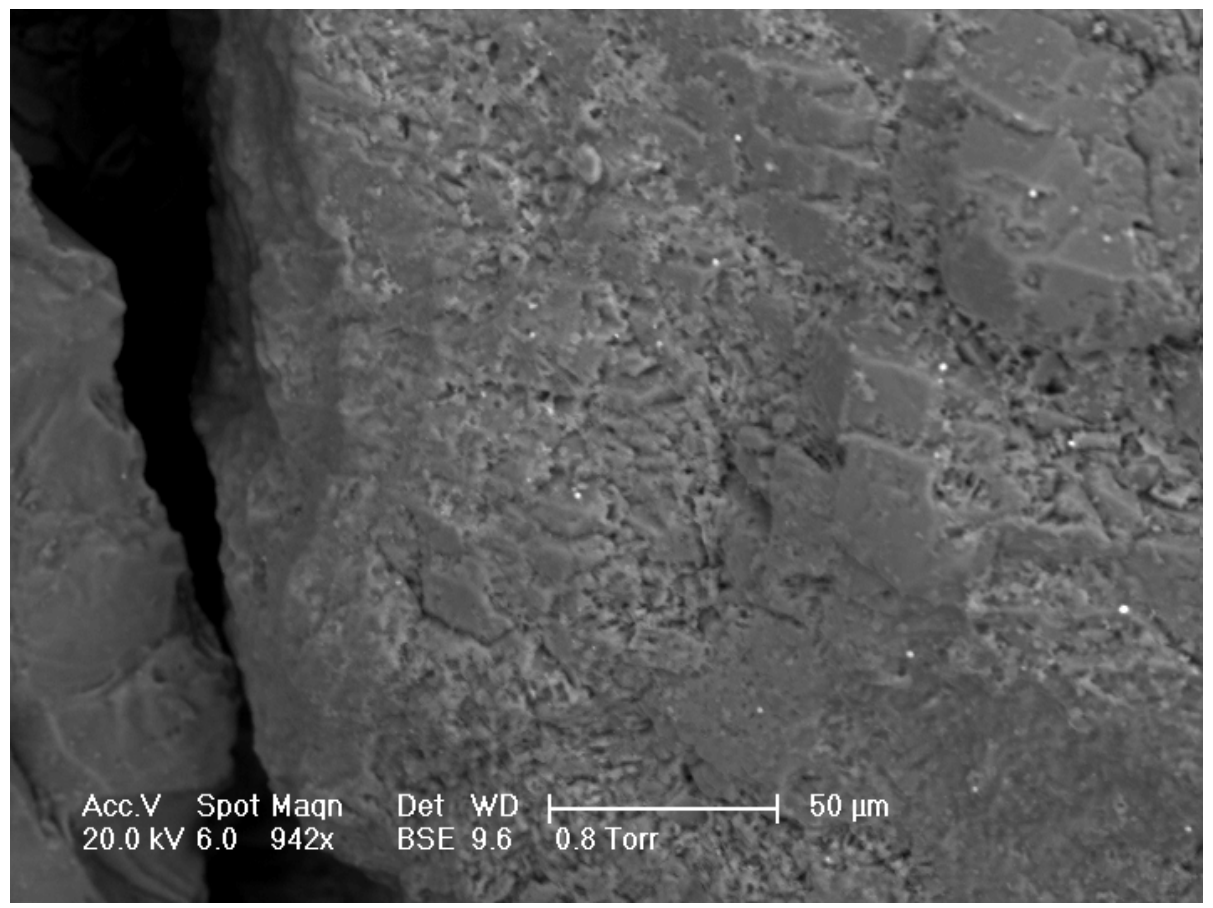

Figure 11 Other sand grain from the same experiment as figures 9 and 10. In the regions with poorly defined dark and bright areas, strong variations in the local Gd content of the surface were registered. Gd-rich and Gdpoor areas were found about $10 \mu \mathrm{m}$ apart from each other. Example spectra are given in figure 12.

EDX spectra were recorded on various spots of the sample. Regions appearing darker in the BSE images typically contained $\mathrm{Si}, \mathrm{O}$ and $\mathrm{Al}$ as main elemental constituents. Localized bright regions on the sand grains could be identified as mineral enclosures containing mainly Ti and $\mathrm{Ba}$ as "heavy" elements. In some spots also $\mathrm{Cu}$ or $\mathrm{Pb}$ could be found as well as some minor quantities of $\mathrm{Fe}$. The low Fe content of the sand can be attributed to the magnetic filtering treatment which was performed on the sand in order to minimize magnetic distortions in the MRI studies. Along with the Ba and Ti also Gd could be detected on some of the bright spots, however in minor quantities. On the BSE-dark areas, no Gd signals were seen in the EDX spectra. In some surface regions with weak and blurred BSE contrast features (such as in figure 11), remarkably strong variations in the Gd content of the surface were found which could be loosely correlated with the brightness of the respective surface areas (see figure 12 for a comparison of two EDX spectra). 


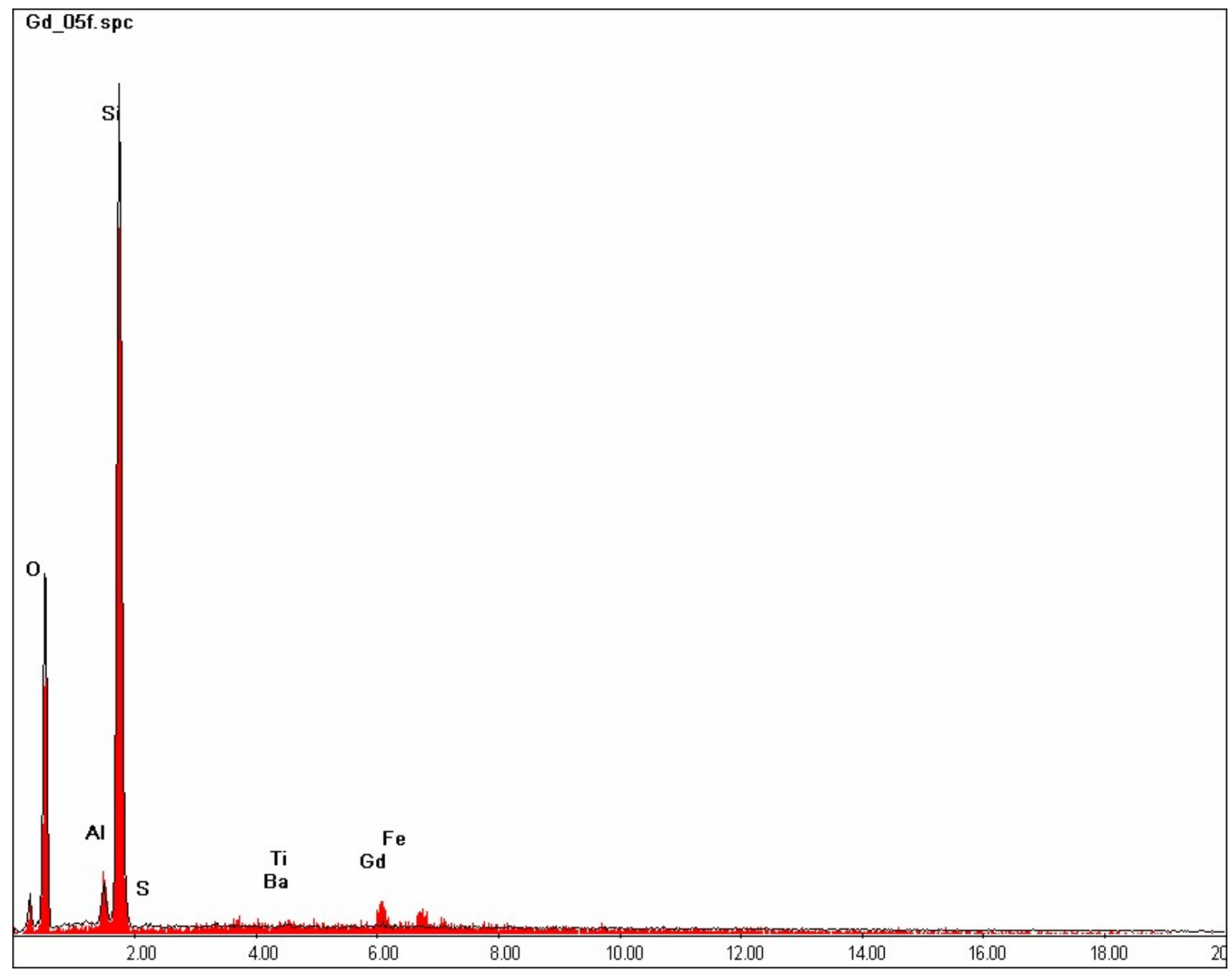

Figure 12 EDX spectra for two neighbouring spots about $10 \mu \mathrm{m}$ apart from each other in the central region of figure 11. Note the Gd-lines in red histogram spectrum and the almost complete absence of such lines in the other spectrum represented by a black line.

The BSE and EDX findings indicate that the concentration of adsorbed Gd in the stable traces formed under flow is below the instrument's sensitivity limit. The higher adsorption capacity of the sand under static conditions, by contrast, seems to be due to local enrichment of Gd on surface features that can be partially associated with enclosures of other (naturally present) "heavy" elements on the sand surface. Local enrichment of adsorbed Gd into such spots can explain the observed "fading" of the MRI contrast as well as the relatively good accessibility of the adsorbed ions to water flow and chemical changes. The fact that the EDX analysis fails to detect the sand surfaces' Gd content after a short exposure to water indicates again the extraordinary high sensitivity of the NMR relaxation time contrast even to minor quantities of adsorbed $\mathrm{Gd}^{3+}$ ions.

\section{$\underline{3.4 \text { Long-term behaviour of injected Gd at different concentrations }}$}

While the concentration of the $222 \mathrm{mg} / \mathrm{l} \mathrm{Gd}^{3+}$ solution in the experiments on the coarse sand exceeded the adsorption capacity of the sand under static conditions, the static sorption capacity still was not fully saturated in the experiments on the fine-grained sand shown in figure 1. In order to study the concentration dependence of the contrast changes at different concentrations, further experiments were conducted with a differently designed static sand cell (see sketch and photo in figure 13). The permanently installed injection wells in this cell 
design were also intended for later sampling of pore water from the wells for chemical analysis.
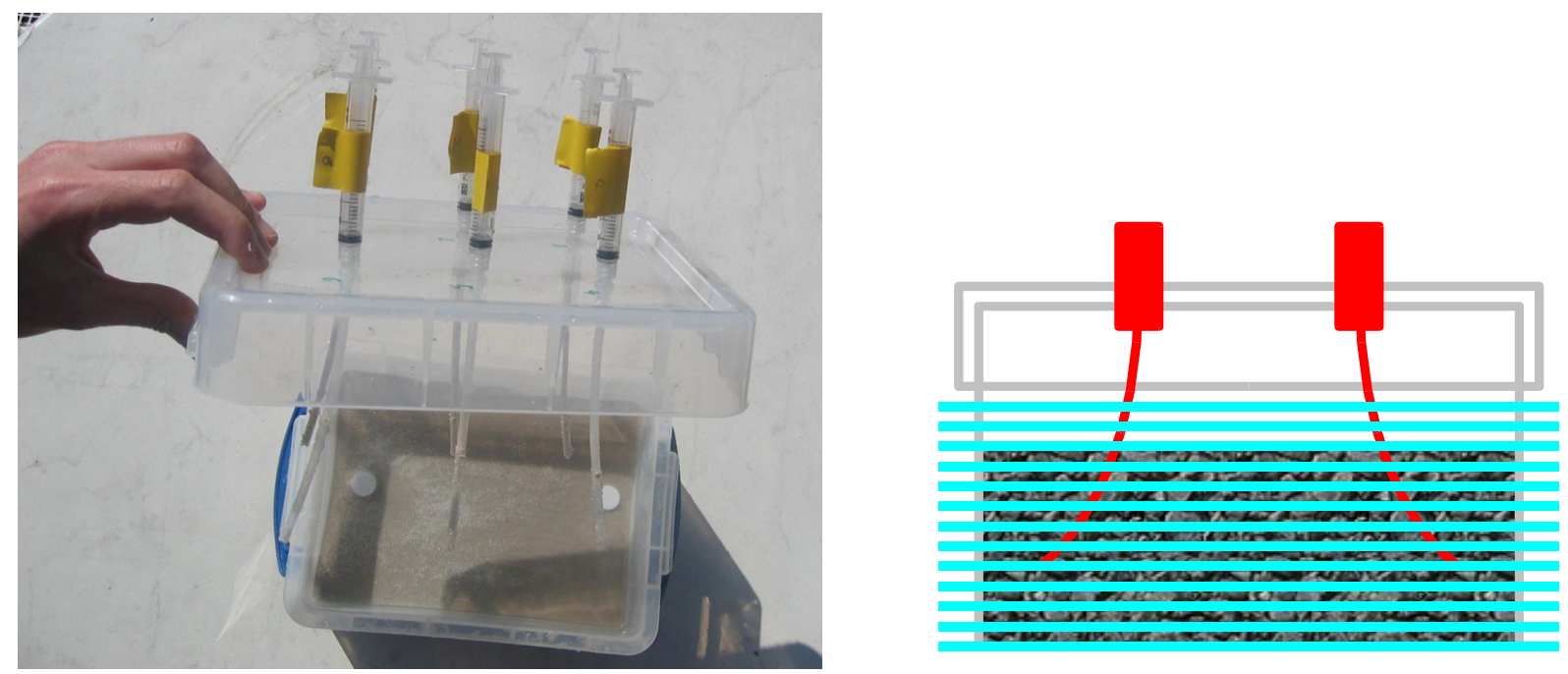

Figure 6. Sample cell with fixed injection wells. Left photograph during disassembly, right: sketch of the seutp along with stack cyan-coloured lines indication orientation of the image layers shown in figure 14 and 15 in the article. Near the two ends, again two reference vials filled with water respectively $\mathrm{Gd}\left(\mathrm{NO}_{3}\right)_{3}$ solution were positioned (white in the photo). The injection wells were connected to PP Luer-Lock fittings screwed into the top of the cell.

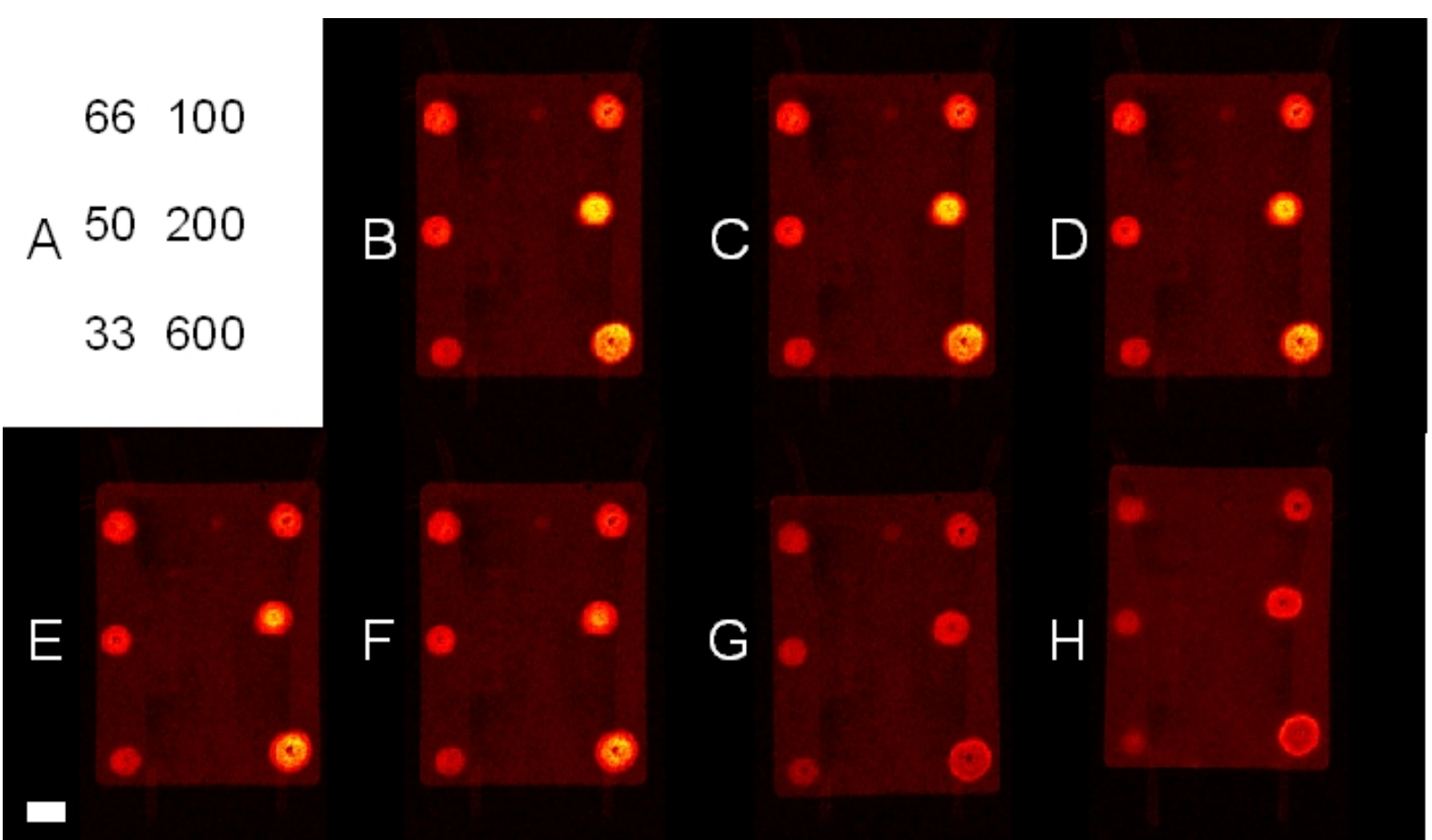

Figure 14 Contrast changes for $\mathrm{Gd}\left(\mathrm{NO}_{3}\right)_{3}$ solutions with different concentrations injected into a water-saturated bed of quartz sand with a grain size of $0.1-0.5 \mathrm{~mm}$. A: $\mathrm{Gd}^{3+}$ concentrations in $\mathrm{mg} / \mathrm{l}$ administered to the sand bed at the different injection sites. B: T1-weighted FLASH image 10 min after the injections, C: after 1h, D: after $1 \mathrm{~h}$ $40 \mathrm{~min}, \mathrm{E}$ : after $2 \mathrm{~h} 50 \mathrm{~min}, \mathrm{~F}$ : After 3 h $50 \mathrm{~min}$, G: after $23 \mathrm{~h}, \mathrm{H}$ : after 3 months. Note that the images $\mathrm{G}$ and $\mathrm{H}$ were acquired in separate scanning sessions so that the exact slice position is not fully reproduced.

All MRI scans in this figure were produced using the following parameters: $\mathrm{TR}=4.4 \mathrm{~ms}$, $\mathrm{Te}=1.8 \mathrm{~ms}$, excitation angle $15^{\circ}$, data matrix: $256 \mathrm{X} 160$ points, 30 slices of $3.33 \mathrm{~mm}$ thickness, in-plane resolution $(1.05 \mathrm{~mm})^{2}$. The bright bar corresponds to $2.5 \mathrm{~cm}$. 


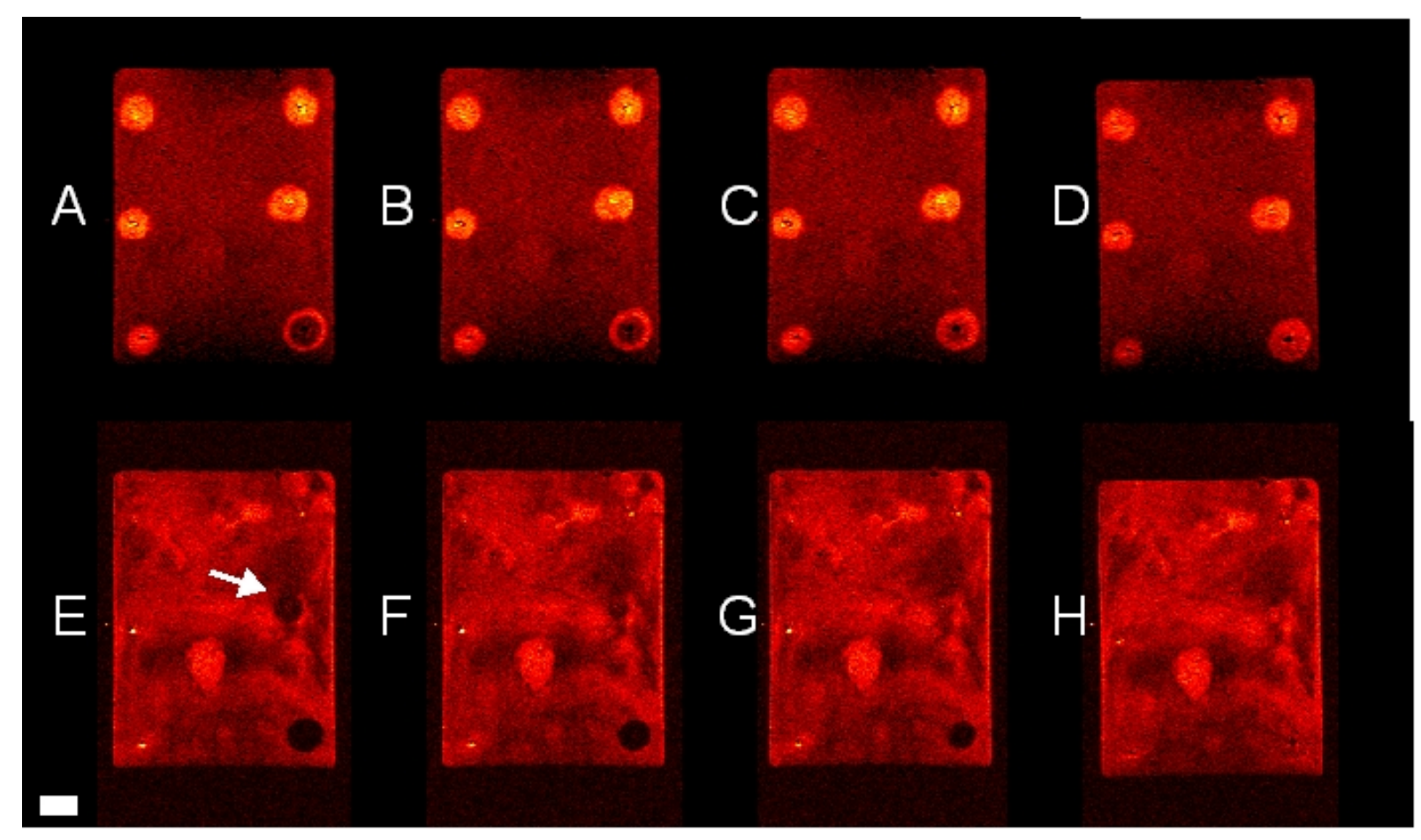

Figure 15 Contrast changes in differently weighted MR images for the sample shown in figure 4. A to D: Spin echo (SE) images with $\mathrm{TR}=1000 \mathrm{~ms}, \mathrm{TE}=17 \mathrm{~ms}$, slice thickness $2 \mathrm{~mm}$ and an in-plane resolution of $1.51 \mathrm{~mm}$ $1.05 \mathrm{~mm}$. A: $15 \mathrm{~min}$ after injection, B: $1 \mathrm{~h} 37 \mathrm{~min}$ after injection, C: $3 \mathrm{~h} 47 \mathrm{~min}$ after injection, D: $23 \mathrm{~h}$ after injection. Note especially the shrinking of the dark (i.e. short T2) core inside the $600 \mathrm{mg} / \mathrm{l}$ injection area. E-H: TSE images with $\mathrm{TR}=3300 \mathrm{~ms}$, TE=96 ms slice thickness $2 \mathrm{~mm}$ and an in-plane resolution of $1.07 \mathrm{X} 1.05 \mathrm{~mm}$. E: $7 \mathrm{~min}$ after the injection. A weakly reduced signal intensity can be observed for the $200 \mathrm{mg} / \mathrm{l}$ injection (near the white arrow) and a strongly reduced signal intensity is seen for the $600 \mathrm{mg} / \mathrm{l}$ injection. F: After $1 \mathrm{~h} 35 \mathrm{~min}$, the signal reduction in the $200 \mathrm{mg} / \mathrm{l}$ injection region has almost vanished, the region with reduced signal intensity for the $600 \mathrm{mg} / \mathrm{l}$ injection has shrunk notably. G: after $3 \mathrm{~h} 45 \mathrm{~min}, \mathrm{H}$ : after $23 \mathrm{~h}$.

Figures 14 and 15 show cross-sections through all injection sites at various times after the injection. In that experiment, the highest $\mathrm{Gd}^{3+}$ concentration was chosen to be $600 \mathrm{mg} / \mathrm{l}$ in order to match the higher sorption capacity of the fine sand which was known from the experiments under flow conditions. However, no indication for spreading of $\mathrm{Gd}^{3+}$ ions outside the original injection area could be found in the MRI scans taken over several hours and in several control sessions up to a few weeks.

This somewhat surprising finding indicates a much bigger ratio between the sorption capacities under static and under flow conditions in the case of the fine sand compared to the coarse sand. Further experiments with even higher concentrations of $\mathrm{Gd}^{3+}$ (see figure 16) indicate a maximal sorption capacity of approximately $440 \mathrm{mg} \mathrm{Gd}^{3+}$ per $\mathrm{kg}$ wet sand (corresponding to a $\mathrm{Gd}^{3+}$ concentration of $700 \mathrm{mg} / 1$ in the solution) under static conditions which can be estimated from comparing the volume of the injection region with the volume with enhanced relaxation contrast after the adsorption equilibrium is reached. 


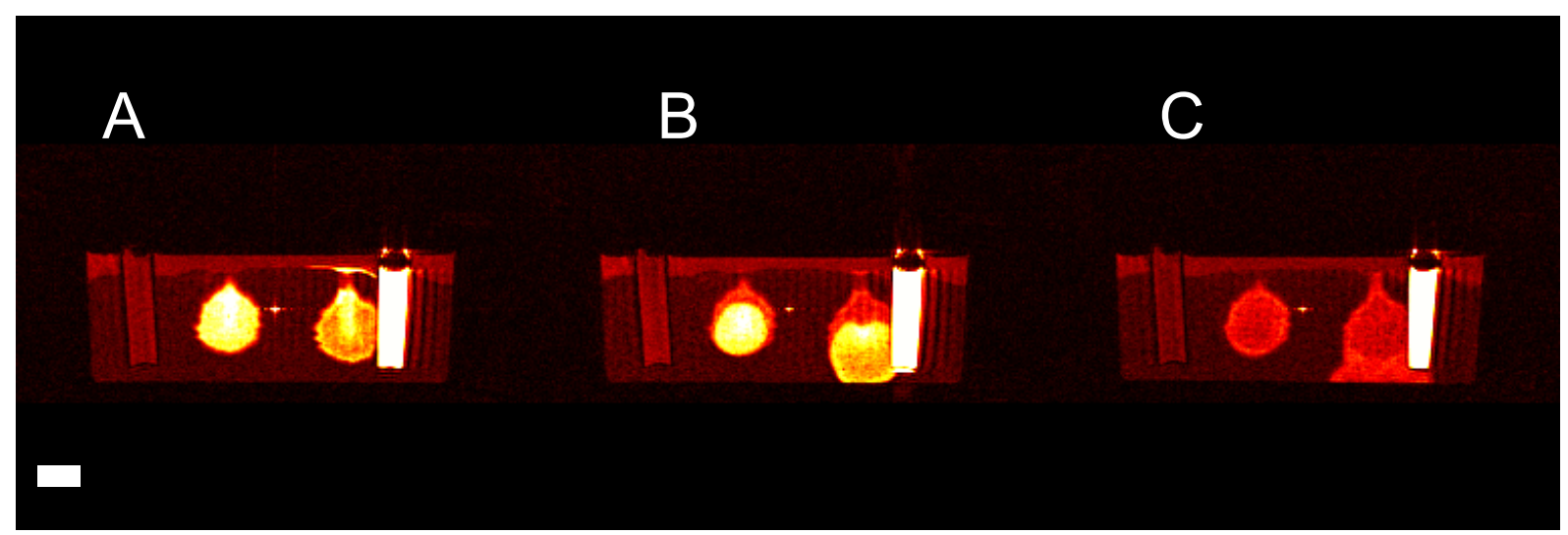

Figure 16. Behaviour of Gd solutions with $\mathrm{Gd}^{3+}$ concentrations of $900 \mathrm{mg} / \mathrm{l}$ (left) and $1800 \mathrm{mg} / \mathrm{l}$ (right, close to reference vial with $200 \mathrm{mg} / \mathrm{l} \mathrm{Gd}$ solution) in fine quartz sand. A: immediately after injection; B: $5 \mathrm{~h} 30 \mathrm{~min}$ after injection in the upper part of the injection regions, a sorption trace remains while the still mobile part of the originally injected $\mathrm{Gd}^{3+}$ ions is travelling downwards in a gravity-driven flow; $\mathrm{C}$ : 1 week after injection, all $\mathrm{Gd}^{3+}$ ions are adsorbed at the sediment. Volume rendering of both the injection regions leads to a sorption capacity of $440 \mathrm{mg} / \mathrm{kg}$ wet sand. FLASH MRI scans with the following parameters: TR $=4.4 \mathrm{~ms}, \mathrm{TE}=1.8 \mathrm{~ms}$, excitation angle $15^{\circ}$, field of view: $240 \mathrm{~mm} \times 150 \mathrm{~mm}$, slice thickness: $2.5 \mathrm{~mm}$ and in-plane resolution: $(0.94 \mathrm{~mm})^{2}$, the bright bar corresponds to $2 \mathrm{~cm}$.

A likely explanation for the much higher static adsorption capacity of the fine sand is the different chemical composition of the two sands: The fine-grained sand sample contains several percent of feldspar while the coarser sand was more or less pure quartz sand. Furthermore, the electron microscopy inspection of the two sand's surfaces indicates a much rougher surface for the fine-grained sand (see figure 9) than for the coarse-grained sand (see figure 17). The sorptive binding of $\mathrm{Gd}^{3+}$ to the feldspar component seems to be weaker than to quarz, while the binding capacity seems to be higher.

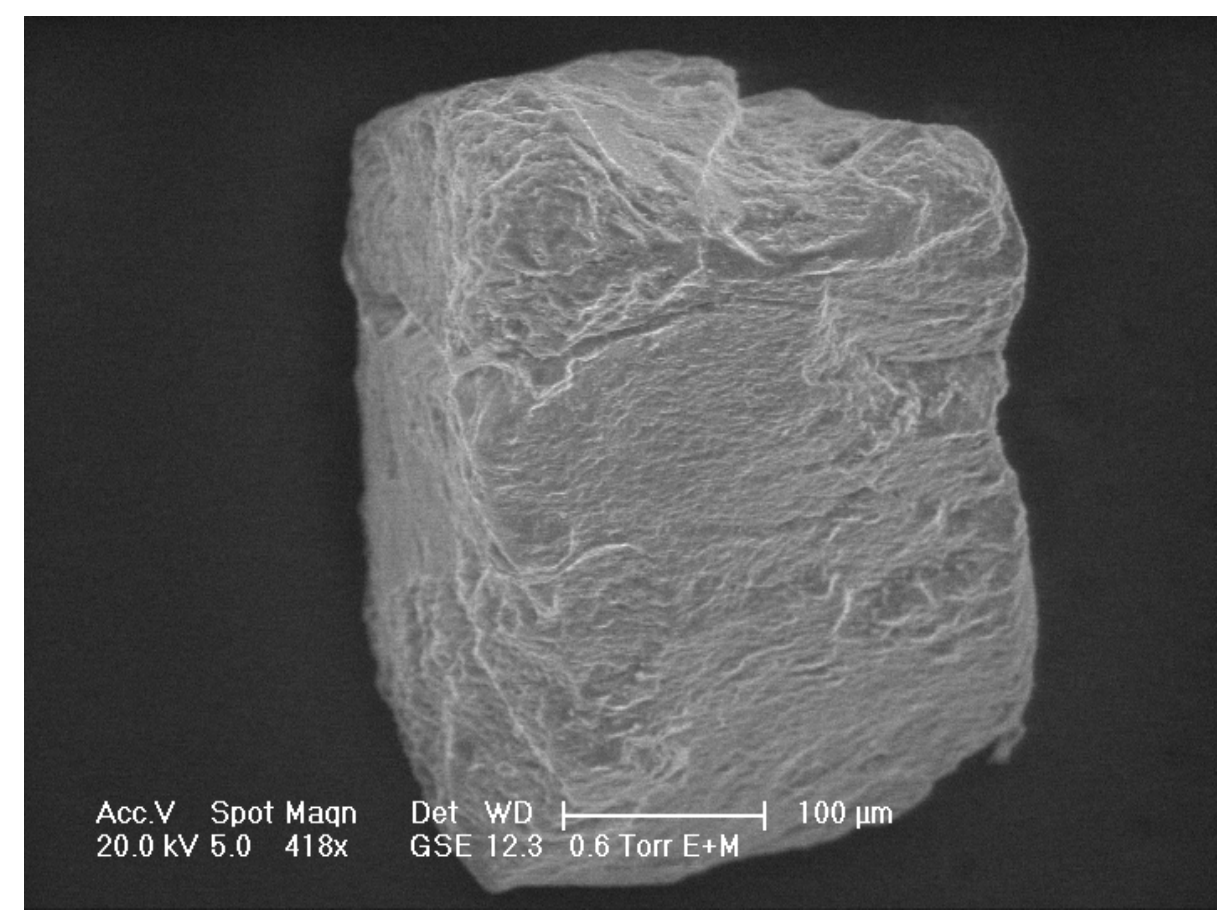

Figure 17. Electron micrograph of a typical grain of the $0.3-0.8 \mathrm{~mm}$ sand used in the experiment. Note the much smoother surfaces compared to the 0.1-0.5 mm material (e.g. in figure 9). 
In the images with different relaxation time weighting, different changes in the contrast behaviour can be observed: The main effect in the T1-weighted FLASH images shown in figure 14 is a decrease over the first day in the contrast between the injection regions and the surrounding sediment. Except for the two highest $\mathrm{Gd}^{3+}$ concentrations injected, this contrast decrease is homogeneous over the whole injection region. For the two highest concentrations, the contrast decrease is not spatially homogeneous but takes place from the outside to the inside as it was already observed in the experiment shown in figure 3. In the T1-weighted spin echo images shown in figure 15 a less pronounced decrease in the contrast between the injection regions and the surrounding sand can be observed. These contrast changes indicate that the T1 difference between the injection regions and their surrounding decreases. Analyses of the signal intensities relative to the reference materials clearly indicate that there is no change in the signal intensity of the surrounding sand. So there must be an increase of the T1 time inside the injection regions. This indicates a loss in relaxivity of the $\mathrm{Gd}^{3+}$ ions during the first day of residence on the sediment. In addition the the T1-increase also an increase in T2 can be observed from the images shown in figure 15: Shortly after injection, the injection regions with the two highest concentrations of $\mathrm{Gd}^{3+}$ appear dark in the strongly $\mathrm{T} 2$-weighted turbo spin echo and for the centre of the injection region, this is also the case in the moderately T2-weighed spin echo. As the inner structure of the high-concentration injection regions fades away in the T1-contrast shown in figure 14, also the dark areas in the T2weighted images go away. The fact that this is the case even in the strongly T2-weighted turbo spin echo data suggests that the change in the T2 of the pore water is more pronounced than in the T1. From the NMR point of view, this is quite understandable from the fact that the time window for $\mathrm{T} 2$ to be significantly reduced by the presence of the adsorbed ions is shorter than the respective time window for T1. Therefore, no complete averaging due to diffusive mixing of the water takes place on the time scale of the $T_{2}$ effect.

\subsection{Outside-in pattern in the contrast change}

A careful analysis of the contrast profiles immediately after the injection indicates that the injection sites are surrounded by a mixing zone with decreasing concentration and a thickness of about $5 \mathrm{~mm}$. This is quite obvious from the contrast in figure 15A and can also be verified from signal profiles taken from the FLASH images. The existence of such a concentration profile on the outside of the injection zones provides an explanation for the outside-in migration direction of the contrast decrease in the injection sites with higher $\mathrm{Gd}^{3+}$ concentrations: The slow adsorption and reorganization process is finished faster in the lower concentration regions. As the amount of $\mathrm{Gd}^{3+}$ is not sufficient to saturate all binding sites, ions diffusing out from the core of the injection region can still be bound to the sediment so that this leads to a depletion of the $\mathrm{Gd}^{3+}$ concentration in the interface region between the inner region with remaining dissolved $\mathrm{Gd}^{3+}$ and the outer region where the $\mathrm{Gd}$ is already immobilized, and the immobilization zone migrates from the outside to the inside.

An analysis of the volumes of the injection regions observed for the different concentrations of $\mathrm{Gd}^{3+}$ in the experiment shown in figures 14 and 15 reveals another interesting feature: In all injections, a solution volume of $3 \mathrm{ml}$ was administered into the sand packing. However, as can be seen from figure 6 , the volume of the region with enhanced spin relaxation decreases systematically with the concentration of $\mathrm{Gd}^{3+}$ ions injected. This finding suggests that the adsorption of $\mathrm{Gd}^{3+}$ ions to the strong binding sites (which we observed in the flow cell experiments) is an extremely fast process (the injections were performed as a matter of 
several seconds). A more detailed investigation of the adsorption kinetics during the injection process is under way and shall be treated in a separate paper.

As already mentioned above, the sample cell with fixed injection wells was also designed for sampling pore water directly from the injection sites after a standing time of several weeks. Due to problems with residual dead volume in the injection wells or the fittings, this turned out to be more difficult than anticipated: As the concentration of the $\mathrm{Gd}^{3+}$ ions in the injected solutions is several orders of magnitude higher than the concentration in the pore water of the sand after a few days. Due to these complications, no systematic relationship between the pore water concentration of $\mathrm{Gd}^{3+}$ and the originally injected concentration could be determined from these samplings. However, the measured values of the $\mathrm{Gd}^{3+}$ concentration indicate a ratio of bound $\mathrm{Gd}^{3+}$ to free $\mathrm{Gd}^{3}$ of over 1000 in all injection regions except the one with the highest concentration where the value may be around 500 .

\section{$\underline{\text { 3.6 Maturing effects in suspensions of superparamagnetic colloids }}$}

As already shortly mentioned above, the post-injection pore-water relaxation time changes for paramagnetic ions injected into quartz sand are not unique to $\mathrm{Gd}^{3+}$ ions but similar contrast changes were also observed for $\mathrm{Cu}^{2+}$ and $\mathrm{Cr}^{3+}$ ions in quartz sand (see figure 4 in the supporting information). Furthermore, similar contrast changes could also be observed in samples where colloidal suspensions of superparamagnetic particles with inorganic surfaces were injected into the sediment: On the left side of the images in figures 2 and 3, one can see the signal intensity changes taking place after the injection of a suspension of superparamagnetic $\mathrm{CoFe}_{2} \mathrm{O}_{4}$ nanoparticles (obtained from Sustec, Darmstadt) into the sediment. Like the $\mathrm{Gd}^{3+}$ ions, also the $\mathrm{CoFe}_{2} \mathrm{O}_{4}$ particles do not move out of the injection region during the observation period. Also, a similar loss in contrast intensity can be observed which takes place on the order of hours. Like for the highly concentrated Gd-solutions, the loss in T1-contrast is also accompanied by a more pronounced loss in T2-contrast visible from TSE and SE data sets. In experiments with polymer-coated $\mathrm{CoFe}_{2} \mathrm{O}_{4}$ nanoparticles, also a complete immobilization in the original injection regions was observed. However, no changes like for the uncoated particles and the paramagnetic ions took place in this case.

\section{Conclusion}

To conclude, we have observed ageing effects for the NMR contrast of adsorbed paramagnetic ions and filtered superparamagnetic colloids. While these effects pose a serious obstacle in quantifying the amount of adsorbed ions or filtered colloids from the relaxation time contrast, the underlying pore water NMR relaxation time changes can provide additional insights into the nature of adsorption mechanisms of different substances to the pore walls of the sediment. From the experiments presented here, we have found evidence for considerable rearrangements of the adsorbed ions on a time scale of hours. Furthermore, different sites with different binding strength exist. This manifests itself in the existence of different sorption capacities under static conditions and under flow. As could be observed in $\mathrm{pH}$-change experiments, all the adsorbed ions are rapidly accessible to changes in the solution chemistry even after very long times of residence on the sediment pores. This suggests that transport of the adsorbed ions to poorly accessible sites (e.g. in microcracks) plays only a minor role in the observed contrast changes. The findings in ESEM and EDX experiments suggest a local enrichment of Gd near naturally occurring impurities in the sand surface as a main reason for the "fading" MRI contrast. However, the sensitivity of the EDX experiment is too low to detect the Gd initially adsorbed to the surface. Further research efforts will therefore need the 
introduction of further complementary methods such as synchrotron microtomography in order to achieve even better sensitivity for the $\mathrm{Gd}^{3+}$ distribution between solution, sand surface and chemical impurities on the sand. At the same time, the fact that MRI is able to observe changes in the distribution of $\mathrm{Gd}^{3+}$ ions at quantities below the sensitivity limit of EDX measurements again shows the excellent sensitivity of MRI in studies of heavy metal adsorption on sediments.

\section{Acknowledgement}

Parts of this work were funded by the DFG (German Science Foundation) under the project grant BA-1592/1-1 at the TU Munich. Furthermore, the practical help by C. Sternkopf (IPC$\mathrm{MS}$ ) and $\mathrm{J}$. Kirstein (preparation of the $\mathrm{Gd}^{3+}$ concentration series in the sand) is acknowledged.

\section{References}

[1] N. Nestle, T. Baumann, A. Wunderlich, R. Niessner, Magnetic Resonance Imaging, 21 (2003) 345-349.

[2] N Nestle, A. Wunderlich, R. Niessner, T. Baumann, Environmental Science Technology 37 (2003) 3972-3977.

[3] I. Bertini, C. Luchinat, G. Parigi 2001 Solution NMR of Paramagnetic Molecules Applications to Metallobiomolecules and Models Current Methods in Inorganic Chemistry (Amsterdam: Elsevier)

[4] M.T.Vlaardingerbroek, J.A. den Boer 1999. Magnetic Resonance Imaging. Theory and Practice. Springer, Heidelberg.

[5] Blümich, B. 2000. NMR Imaging of Materials. Clarendon, Oxford.

[6] D. Michel, H. Pfeifer, Zeitschrift für Naturforschung 20a: (1965) 200-226.

[7] H. G. Hertz, Nuclear magnetic relaxation spectroscopy, in "Water: A Comprehensive Treatise" (F. Franks, Ed.), Vol. 3, Chap. 7, Plenum, New York (1973)

[8] R. L. Kleinberg, W. E. Kenyon, P. P. Mitra, J. Magn. Reson. A 108 (1994) 206-214.

[9] P. Roose, J. Van Craen, G. Andriessens, H. Eisendrath, J. Magn. Reson. A 120 (1996), 206-213.

[10] T.R. Bryar, C.J. Doughney, R.J. Knight (2000), J. of Magn. Reson. 142 (2000) 74-85.

[11] R.D. Riordan, M. Khonsari, J Jeffries, G.F. Maskell, P.G. Cook, Br J Radiol. 77 (2006) 991-999.

[12] S.E. Oswald, M.B. Scheidegger, W. Kinzelbach, Transport in Porous Media 47 (2002) 169-193.

[13] N. Nestle NMR studies of transport and remediation processes in soil and sediments in "Soil and Sediment Remediation" (ed. P. Lens, T Grotenhuis und H. Tabak, IWAP Publishing, London, 2005),

[14] M.S. Olson, R.M. Ford, J.A. Smith, E.J. Fernandez, Environmental Science Technology 39 (2005) 149-154. 